\title{
Managing Environmental Information in the Age of Outsourcing ${ }^{1}$
}

\author{
Scott Perkins, Mandy Whorton, Gus Williams ${ }^{2}$, and Karen Smith

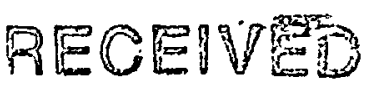 \\ OCT 131999 \\ OSTI \\ Argonne National Laboratory \\ Environmental Assessment Division \\ 1075 South Yukon Street, Suite 209 \\ Lakewood, Colorado 80226 \\ (303) 986-1140; email: sperkins@anl.gov \\ http://www.ead.anl.gov
}

The submitted manuscript has been created by the University of Chicago as Operator of Argonne National Laboratory ("Argonne") under Contract No. W-31-109-ENG-38 with the U.S. Department of Energy. The U.S. Government retains for itself, and others acting on its behalf, a paid-up, nonexclusive, irrevocable worldwide license in said article to reproduce, prepare derivative works, distribute copies to the public, and perform publicly and display publicly, by or on behalf of the Government.

\begin{abstract}
As more data gathering, analysis, and tracking tasks are outsourced, the need for multiple contractors and military personnel to input, update, access, store, and track information is becoming critical to efficient functioning and managing of environmental projects and programs at military installations. This paper presents two case studies detailing the way two organizations - the Rocky Mountain Arsenal (RMA) in Colorado, and the $611^{\text {th }}$ Air Support Group (611 ASG) in Alaska - are managing complex data using webbased technology.

RMA is involved in one of the largest environmental cleanup programs in the Department of Defense. As such, large volumes of environmental data and documents must be generated, stored, and tracked. Often these documents are prepared by multiple contractors and are reviewed by several parties or groups. To manage environmental information and to ensure that it meets compliance requirements more efficiently, RMA has developed an electronic document tracking and distribution system. This system allows access to up-to-date information, including a detailed review of all pertinent regulatory and other requirements at RMA. The dynamic system includes milestones, review deadlines, submission deadlines, and other requirements for managing the environmental program.

The 611 ASG manages more than 30 remote installations in Alaska, many of which are operated by contractor personnel. These installations contain hundreds of buildings that are constantly being modified because of exposure to harsh, arctic climates; some of them have been determined to be eligible for the National Register of Historic Places. To meet regulatory requirements for cultural resources management, as well as engineering requirements for upkeep of buildings, a database was developed to store and analyze building data. The database has a web-based interface that allows anyone with the correct access codes to input new data, modify existing data, or query the database using a number of standard reports. This system allows the 611 ASG to centrally manage its building information while also permitting installation contractors to update and use data through the Internet from their remote locations.
\end{abstract}

\section{Introduction}

Over the last 20 years, the military has been subject to two strong trends: reductions in budget and available manpower and increased emphasis on environmental management and compliance. The military has adapted to these conditions by (1) using more efficient tools to manage environmental problems and (2) outsourcing many of the projects that formerly were done by military and civilian Department of Defense personnel. These actions have diversified services and increased the number of contractors that provide them, decentralized available environmental information, and made the military's management of projects more challenging. Two case studies are presented to show how a smaller workforce, if provided with low-cost but

\footnotetext{
${ }^{\mathrm{I}}$ Work supported under a military interdepartmental purchase requisition from the US Department of Defense (Rocky Mountain Arsenal and $611^{\text {th }}$ Air Support Group) through US Department of Energy contract W-31-109-Eng-38.

${ }^{2}$ Argonne National Laboratory, 9700 South Cass Avenue, Argonne, Illinois 60439; (630) 252-4609
} 


\section{DISCLAIMER}

This report was prepared as an account of work sponsored by an agency of the United States Government. Neither the United States Government nor any agency thereof, nor any of their employees, make any warranty, express or implied, or assumes any legal liability or responsibility for the accuracy, completeness, or usefulness of any information, apparatus, product, or process disclosed, or represents that its use would not infringe privately owned rights. Reference herein to any specific commercial product, process, or service by trade name, trademark, manufacturer, or otherwise does not necessarily constitute or imply its endorsement, recommendation, or favoring by the United States Government or any agency thereof. The views and opinions of authors expressed herein do not necessarily state or reflect those of the United States Government or any agency thereof. 


\section{DISCLAIMER}

Portions of this document may be illegible in electronic image products. Images are produced from the best available original document. 
powerful, user-friendly web-based programs, can effectively manage the ever-increasing quantity of environmental information necessary for operations.

\section{Rocky Mountain Arsenal, Colorado}

Rocky Mountain Arsenal (RMA) is the site of one of the largest environmental cleanup programs in the Department of Defense. The arsenal staff is required to generate, store, and track large volumes of environmental data and documents in support of the environmental compliance program. Often these documents are prepared by multiple contractors and are reviewed by several parties or groups. Perhaps the biggest obstacle to efficient management of environmental information at RMA is the magnitude of the operation. Three parties - the Army, Shell Oil Company, and the U.S. Fish and Wildlife Service - oversee the multi-billion-dollar cleanup. RMA has both an operations contractor and remedy implementation management contractor, as well as a myriad of subcontractors working on the site. Past investigative work and current operations have generated thousands of documents, many of which play a role in environmental compliance and management. Disseminating this vast accumulation of information to all appropriate personnel and managing it to ensure regulatory compliance are significant logistical challenges.

To more efficiently manage environmental information and to ensure that it is meeting compliance requirements, RMA has developed a web-based document tracking and environmental compliance aid for its environmental compliance office. The intranet system improves efficiency and is based on and expands the facility's Environmental Compliance Program. It is designed as a single source for virtually all information necessary for environmental compliance. This intranet site provides up-to-date information, including a detailed review of all pertinent regulatory requirements and status of compliance actions at RMA. The dynamic system includes documents containing current compliance requirements, as well as milestones, review deadlines, submission deadlines, and other requirements for managing the Environmental Compliance Program. As Figure 1 indicates, it provides detailed regulatory information, all relevant sitewide and project-specific documents, reporting requirements, a description of auditing programs and associated checklists, and other necessary information.

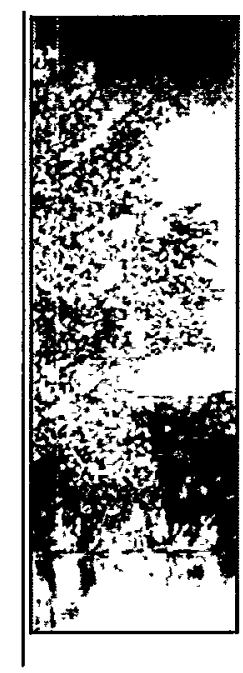

Rocky Mountain Arsenal Environmental Compliance

\footnotetext{
The Rocky Mountain Arsenal Environmental Compliance Intranet is intended

To facitite cavironmental compliance by providing cavironmental regulat

project-specific compliance requirements, access to important documents and

other necessary information.

Rocky Mountain Arsenal Intranet

Contents \& Features

- Who's Who

- Environmental Statutes, Regulations, and Executive Orders

- RMA Specific Regulatory Documents

- Site-Wide Documents

- Project-Specific Documents

- Specific ROD Projects and Associated Compliance

- Reporting Requirements/Notifications

- Environmental Compliance Subject Areas and Auditing

- Glossary/Acronym List
}

FIGURE 1 Rocky Mountain Arsenal Environmental Compliance Intranet Home Page 
The RMA intranet site has been designed to accommodate a number of potential users, although it is currently used exclusively by environmental compliance personnel. Whether the user is an environmental compliance expert or an upper-level manager with little environmental experience, the site provides a logical progression of choices to lead the user to the desired information. Consequently, a number of paths can be used to obtain a given piece of information. This feature was deemed critical to the project's success. Flexibility and a logical structure has vastly increased the system's utility. Operation and use of the site requires no specialized hardware or software.

The primary goal of this site is to provide the user with a simple, accessible roadmap to all necessary environmental compliance information for a given project or program. For example, the Comprehensive Environmental Response, Compensation and Liability Act (CERCLA) Record of Decision (ROD) requires that 31 specific remedial projects be implemented at RMA. One of these projects is the construction of a hazardous waste landfill. From the main page, the user can easily navigate to a page dedicated to the hazardous waste landfill (see Figure 2). This page includes detailed project and site descriptions, a list of dependent projects, compliance deadlines, and ROD regulatory requirements. It also provides links to the project's $100 \%$ design document, the landfill operations manual, and other documents containing pertinent regulatory requirements. Summaries of all relevant regulations (e.g., RCRA, CERCLA, TSCA) and links to the complete texts of statutes and regulations are also accessible.

To review the criteria against which the RMA Environmental Compliance Office will evaluate environmental compliance for the project, a few clicks of the mouse will take the user to a series of 21 compliance checklists. These checklists are categorized on the basis of the Army's Environmental Compliance Assessment System (ECAS) and are general and programmatic in nature. If the user wishes to see more detailed compliance checklists, a link is provided to the voluminous ECAS checklists maintained on the Internet. As the U.S. Environmental Protection Agency, State of Colorado, Army, and RMA perform compliance assessments, all findings relevant to this particular project site will also be available. Information that previously would have taken weeks to compile is now immediately available from one source.

Because a user may not know which documents contain the desired compliance information, the system provides a search function. For example, if a user is concerned about waste pesticide disposal, a site-wide search will turn up all relevant information, including the RMA Pest Management Program, which mandates that waste pesticides be disposed in accordance with the RMA Site-Wide Waste Management Program. The Site-Wide Waste Management Program references numerous subcontractor waste management documents, which are also available at the intranet site. Although not currently available in the beta version of the site, RMA plans to add complete regulatory references (such as RCRA and FIFRA), pesticide spill contingencies, and additional handling precautions. All of these documents would be highlighted by the search engine and available in searchable PDF format for review or download. 


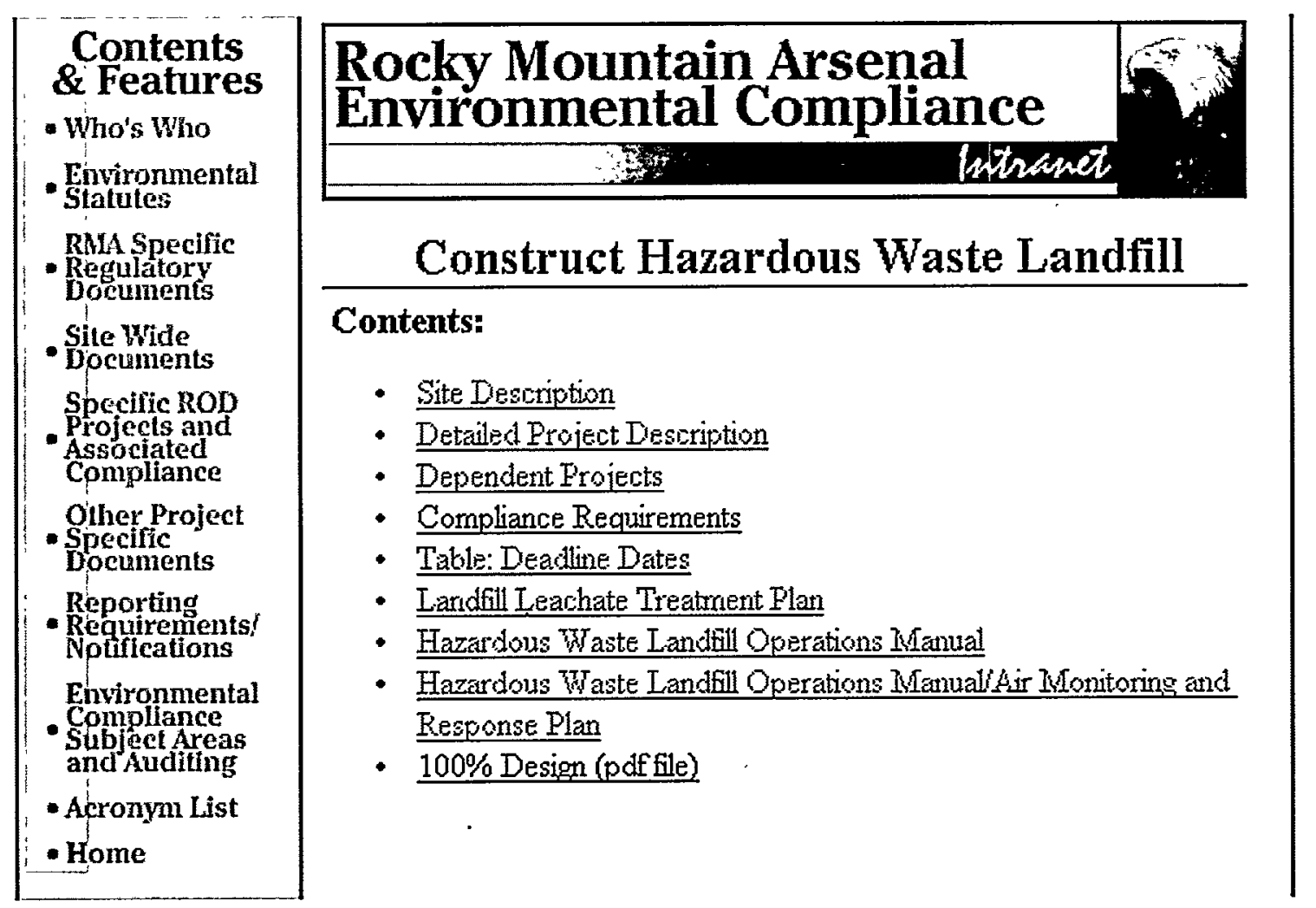

FIGURE 2 Rocky Mountain Arsenal Environmental Compliance Intranet ROD Project Page

If desired, the RMA web tool could be expanded into many different areas, such as health and safety or operations management. It could also be made completely interactive to facilitate collation and manipulation of data and documents. This system can also be equipped with increased security controls to limit access at various levels as necessary. (Security is currently controlled through a central password that allows access to the entire site.)

\section{$611^{\text {th }}$ Air Support Group, Alaska}

The mission of the 611 ASG is to provide communication, engineering, logistics, environmental, financial, and program management support to maintain combat readiness for remote Alaska, the Eleventh Air Force, and the North American Aerospace Defense Command (NORAD). The $611 \mathrm{ASG}$, which is based at Elmendorf AFB in Anchorage, is responsible for the operation and management of more than 40 remote sites that include forward operating locations, active airfields, short-range and long-range radar sites, and inactive or abandoned sites. These sites are widely dispersed across Alaska, including the Aleutian Islands, and represent the largest cumulative "base" in the Pacific Air Force Command (PACAF). On-site management of the active installations has been outsourced to small crews of contractor personnel that perform many functions, including building maintenance, radar operation, meal preparation, land management, and all other activities associated with running a small installation. Program managers at the 611 ASG in Anchorage oversee contractor activities and monitor activities at inactive sites from a distance. 
All of the 611 ASG installations are associated with the continental air defenses developed during the early phases of the Cold War. They provided the first line of defense against a potential Soviet bomber attack over the polar region. Radar stations provided early warning of bomber attack, and forward operating bases were established for fighter-interceptor aircraft to defend against Soviet bombers. The important historical role of these installations has been formally recognized in agreements between the $611 \mathrm{ASG}$ and the Alaska State Historic Preservation Office (SHPO). To manage its historic and prehistoric resources, including numerous historic structures of the World War II and Cold War eras as well as archaeological sites, the 611 ASG developed a database to identify the key characteristics of its cultural resources and to compile additional engineering data for the management of active facilities. The database allows personnel at the 611 ASG to oversee the maintenance of its installations and meet its regulatory requirements for cultural resources management.

The basic database consists of tabular and image data for all buildings at the installations under 611 ASG control. The focus is on cultural resource information obtained from data forms prepared for the Alaska SHPO, but the database also includes other engineering data, such as scheduled maintenance and equipment components. Data can be entered and reviewed in realtime over the web. Input screens provide a number of pull-down menus and other features that reduce data entry errors. Reviewing data is also easy; the report function (which will be expanded) allows the user to query particular parts of the database and prepare a standardized report, including a picture of the facility. Figure 3 shows a partial summary report for one of the installations. A detailed report is also available.

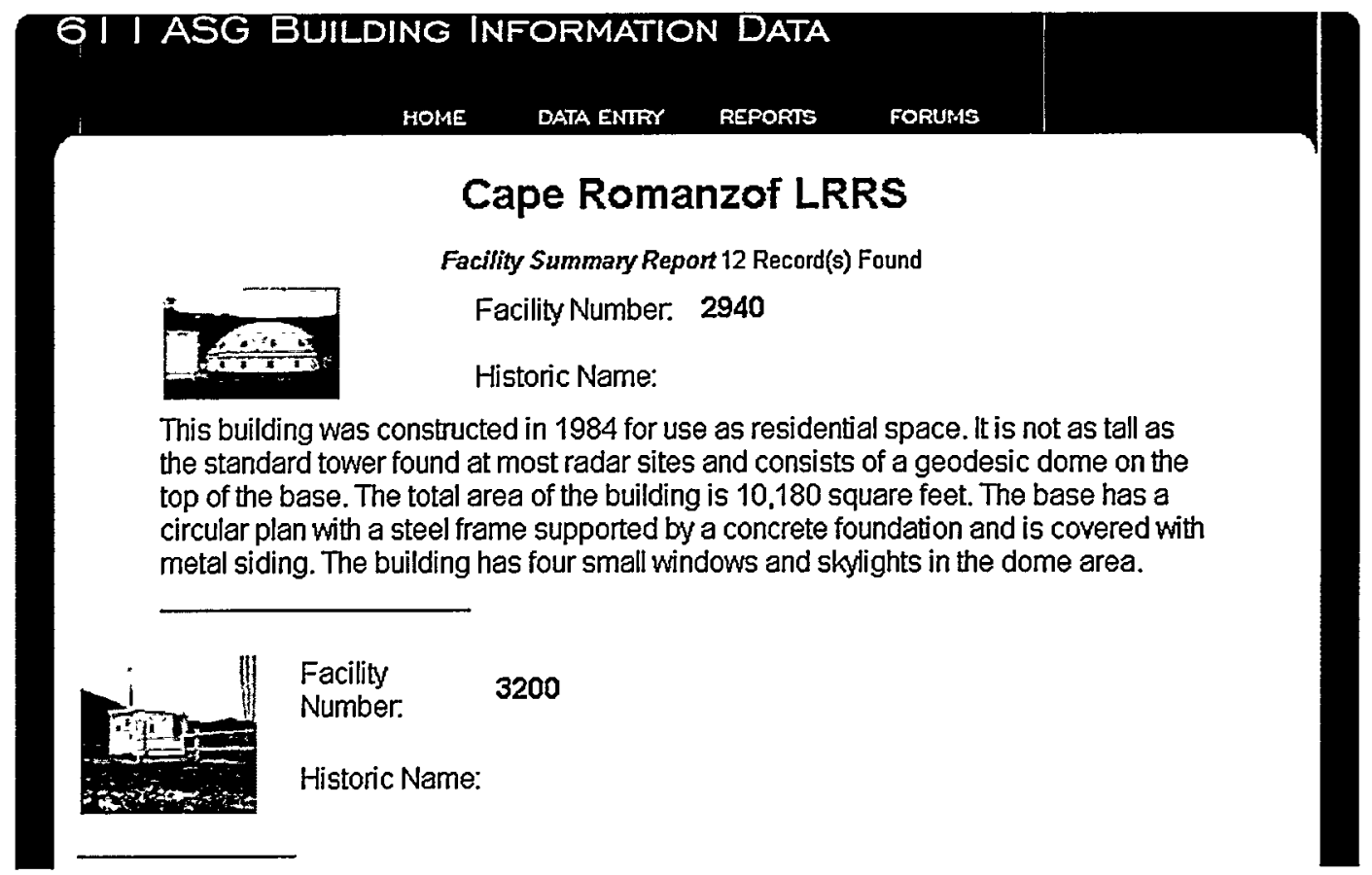

\section{FIGURE $3 \quad 611^{\text {th }}$ Air Support Group Building Database Summary Report Page}

The web site runs on standard computer equipment - a 333-Mhz Pentium II dual processor running Windows NT ${ }^{\mathrm{TM}}$ with Internet Information ${ }^{\mathrm{TM}}$ Server 4 as the web server. The database is a standard Microsoft Access ${ }^{\mathrm{TM}}$ database with a web application interface created in 
Cold Fusion Studio ${ }^{\mathrm{TM}}$. The Cold Fusion ${ }^{\mathrm{TM}}$ Server software resides on the web server to convert the Cold Fusion ${ }^{\mathrm{TM}}$ language into HTML for browsing over the Internet.

The site is extremely easy to maintain because it uses the Internet to perform data entry, including the uploading of pictures. Data and pictures are available immediately after entry by any user. Almost the entire web site, including the pull down menus and menus on the side, is stored in the Access ${ }^{T M}$ database so that updating fields to add additional menu options or other information can be done in the database itself without additional web programming.

Contractors at the remote installations and managers at 611 ASG headquarters access the same information about the buildings at each installation. The database can be accessed from any computer with an Internet connection and standard browser software, but security measures allow the 611 ASG to assign various levels of access to the database and to track database usage. For example, some users are only able to query the database, while others are allowed update privileges.

Because of the utility of the system in managing cultural resources and limited engineering data, the 611 ASG plans to expand the existing database to add additional equipment/machinery data fields and to expand search and report capabilities. Other areas of potential expansion include (1) live links to other databases; (2) addition of clickable maps of facilities and archaeological sites; (3) expansion of existing content to include additional photos, imagery, or fields; (4) expansion of the database to cover additional installations, such as Elmendorf or Eilsen; and (5) addition of other types of data, such as real property, wetlands, monitoring, solid waste management units, or other Installation Restoration Program data.

\section{Conclusion}

These web-based tools for managing data and documents are inexpensive ways to help optimize environmental management. They run on standard equipment and use commonly available software. They are easy to update and provide an excellent means to disseminate critical information to all necessary personnel, regardless of their organizational or geographic locations.

As manpower and financial resources continue to be limited and as technology continues to advance, it will become more apparent that web-based data management tools will be essential in many management and oversight areas. This technology will continue to be used to develop integral management tools for the future.

\section{Acknowledgments}

The authors wish to acknowledge the contributions of Jim Kuiper, Andy Huttenga, Pam Richmond, and Jennifer Herbert, all from Argonne National Laboratory, Argonne, Illinois, who worked on the programming and design of the sites. We would also like to thank the sponsors of these projects - Brian Anderson, ROD/Refuge Compliance Manager at Rocky Mountain Arsenal, and Capt. Christopher Pleiman, Chief, Environmental Planning at the 611 CES/CEV for their support. 